\title{
TRADICIÓN Y NORMATIVA DEL CONCEJO DE VALDETUÉJAR: LAS ORDENANZAS CONCEJILES
}

\author{
Rubén Esteban LÓPEZ PÉREZ \\ Universidad de León
}

\begin{abstract}
RESUMEN: Las ordenanzas concejiles han sido consideradas como la expresión escrita de toda una tradición y normativa que hunde sus raíces en el Derecho Consuetudinario, las cuales constituyen para los investigadores una de las mejores fuentes de las que disponemos para conocer la organización económica y social de las comunidades rurales durante la Edad Moderna. En el presente trabajo utilizaremos las ordenanzas que se han conservado para el concejo de Valdetuéjar, en la Montaña Oriental leonesa, con objeto de llevar a cabo una aproximación lo más fidedigna posible en este sentido.
\end{abstract}

PALABRAS CLAVE: Ordenanzas concejiles, concejo de Valdetuéjar, Derecho Consuetudinario, organización económica y social.

ABSTRACT: Council laws have been usually considered as the written expression of a tradition and regulations which are related to traditional rights. According to this, those laws are used by the researchers as a great resort so as they can understand the economical and social organization of rural regions all along the Modern Age. In this essay we will use the council laws which have survived in the council of Valdetuéjar (Eastern Mountain of León) in order to study in detail the structures of this territory.

KEYWORDS: Council laws, council of Valdetuéjar, Traditional Rights, economical and social organization.

\section{EL CONCEJO DE VALDETUÉJAR}

\section{El medio geográfico como condicionante de la actividad económica:}

Como es bien sabido, las condiciones morfológicas como la altitud, la orografía, el clima,... determinan en gran medida el tipo de economía que impera en una zona $^{1}$. En este sentido, las comunidades de montaña, entre las que se encuentra los

${ }^{1}$ Pérez Álvarez, M. J. (1996). La montaña noroccidental leonesa en la Edad Moderna. León: Universidad de León, p. 113. 
pueblos pertenecientes al Concejo de Valdetuéjar ${ }^{2}$, tuvieron que acomodar su desarrollo a las limitaciones impuestas desde el medio físico, buscando en la riqueza ganadera y sus posibilidades lo que les era negado por la actividad agrícola y el propio terrazgo. De ahí que, a diferencia de otros modelos, la ganadería sea aquí el marco fundamental y básico en las relaciones político-sociales de estas comunidades, las cuales, a pesar de las limitaciones del espacio físico fueron capaces de reproducirse durante siglos gracias a un férreo control comunitario sobre el medio, a su propia autorregulación política y a un sistema de colectivización de prácticas y recursos ${ }^{3}$.

El arraigo de sus organizaciones concejiles y el rico y variado articulado de su ordenamiento local se pueden considerar como los pilares básicos sobre los que se asienta el desarrollo de estas comunidades ganaderas caracterizadas por una menor polarización y por lo reducido de unas unidades productivas que parecen aceptar como imprescindible la implantación de férreos sistemas colectivizadores bajo la total dependencia del Derecho Consuetudinario. En este sentido, uno de los factores estructurales que más contribuyó a mantener esa igualdad, sin que ello suponga negar la existencia de distintos niveles de riqueza, fue la distribución social de los medios de producción y en especial de la tierra productiva entre la que ocupa un lugar destacado la considerada como comunal o administrada por los Concejos ${ }^{4}$.

A continuación mostramos diversas gráficas en las que podemos observar la distribución del terrazgo en el concejo de Valdetuéjar, haciendo una distinción entre los huertos, la tierra trigal, centenal, prados, pasto común, puerto arrendado y tierra inculta. En este aspecto, merece destacarse el peso de la propiedad administrada por el concejo (pasto común y puertos arrendados), la cual supone un $37,76 \%$ sobre el total, frente a un $62,24 \%$ de tierra de propiedad privada. $\mathrm{Si}$

${ }^{2}$ El concejo de Valdetuéjar, de jurisdicción señorial, se componía en la Edad Moderna de los siguientes núcleos: la villa de Renedo, sede del corregidor, Ferreras del Puerto, La Mata de Monteagudo, Las Muñecas, El Otero, La Red, San Martín, Taranilla, Villa del Monte y Prado de la Guzpeña.

3 Para Pérez Álvarez, M. J. (1996), La montaña..., Op. cit., p. 163, En aquellos lugares donde hay una importante actividad agrícola, la ganadería tendrá un menor peso, puesto que sólo se necesitan los animales imprescindibles para el tiro, mientras que los demás son fuerza sobrante a la que hay que alimentar y dedicarle un espacio, espacio que precisamente puede ir en detrimento de la agricultura. En este tipo de explotaciones el ganado es para autores como SLICHER VAN BATH, B. H. (1974). Historia agraria de Europa Occidental 500-1850. Barcelona: Ediciones Península, p. 414.

4 Rubio PÉrez, L. M. (1993). El sistema político concejil en la provincia de León. León: Ediciones Lancia, S.A., p. 24. 
descendemos al caso concreto de los 5 pueblos del concejo para los que disponemos de ordenanzas concejiles los datos son los siguientes: Ferreras del Puerto (49,51\% común y 50,49\% privada), La Mata de Monteagudo (15,19\% común frente a $84,81 \%$ privada), Prado de la Guzpeña (43,26\% frente a $56,74 \%$ ), San Martín de Valdetuéjar (42,1\% frente a 57,9\%) y la Villa del Monte $(51,81 \%$ frente a $48,19 \%)^{5}$.

Cuadro 1. Distribución del terrazgo en el Concejo de Valdetuéjar (en heminas)

\begin{tabular}{rrrrrrrrr}
\hline$A$ & $B$ & $C$ & $D$ & $E$ & $F$ & $G$ & $H$ & $I$ \\
\hline 127,8 & 3073,5 & 9703,4 & 5108,8 & 5648,5 & 5302 & 32 & 28996 & 2677,2 \\
\hline
\end{tabular}

A, Huertos; B, Tierra trigal; C, Tierra centenal; D, Prados; E, Pasto común;F, Puerto arrendado; G, Tierra inculta; H, Total (heminas); I, Total (hectáreas)

Gráfico 1. Distribución del terrazgo en el Concejo de Valdetuéjar

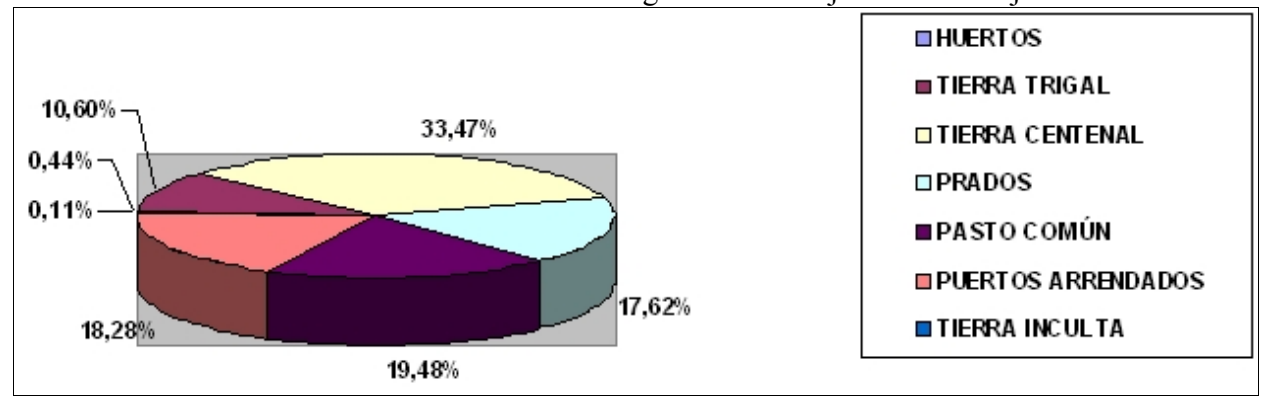

Cuadro 2. Distribución del terrazgo en los pueblos del Concejo de Valdetuéjar que conservan sus ordenanzasd concejiles (heminas)

\begin{tabular}{lrrrrrrrr}
\hline \multicolumn{1}{c}{} & $A$ & $B$ & $C$ & $D$ & $E$ & $F$ & $G$ & $H$ \\
\hline Ferreras del Puerto & 4,6 & 36,8 & 824,125 & 376,6 & 668 & 550 & 2460,1 & 229,5 \\
La Mata de Monteagudo & 19,2 & 66,5 & 1400,19 & 613,6 & 4 & 372 & 2475,5 & 230,3 \\
Prado de la Guzpeña & 5,125 & 824,25 & 198,5 & 418 & 1102,5 & 0 & 2548,4 & 236,2 \\
S. Martín de Valdetuéjar & 14,5 & 169,9 & 640,125 & 539,5 & 392 & 600 & 2356 & 215 \\
Villa del Monte & 4,3 & 28,6 & 1318 & 379,4 & 1060 & 800 & 3590,3 & 335,4 \\
\hline
\end{tabular}

A, Huertos; $B$, Tierras trigales; $C$, Tierras centenales; D, Prados; E, Pasto común y tierra inculta; F, Puerto arrendado; G, Total (heminas); H, Total (en hectáreas)

${ }^{5}$ En este aspecto PÉrez García, José Manuel (1998). Un modelo social leonés en crecimiento. La Vega Baja del Esla entre 1700 y 1850. León: Universidad de León, pp. 35-36; también comprueba la presencia de una importante propiedad colectiva para su zona de estudio. Si bien la situación es muy desigual de unas comunidades a otras, aún nos encontramos con que los concejos detentan el $51 \%$ del espacio, lo que para esta zona es un panorama poco común. 
Gráfico 2. Distribución del terrazgo en los pueblos del Concejo de Valdetuéjar que conservan sus ordenanzasd concejiles (heminas)

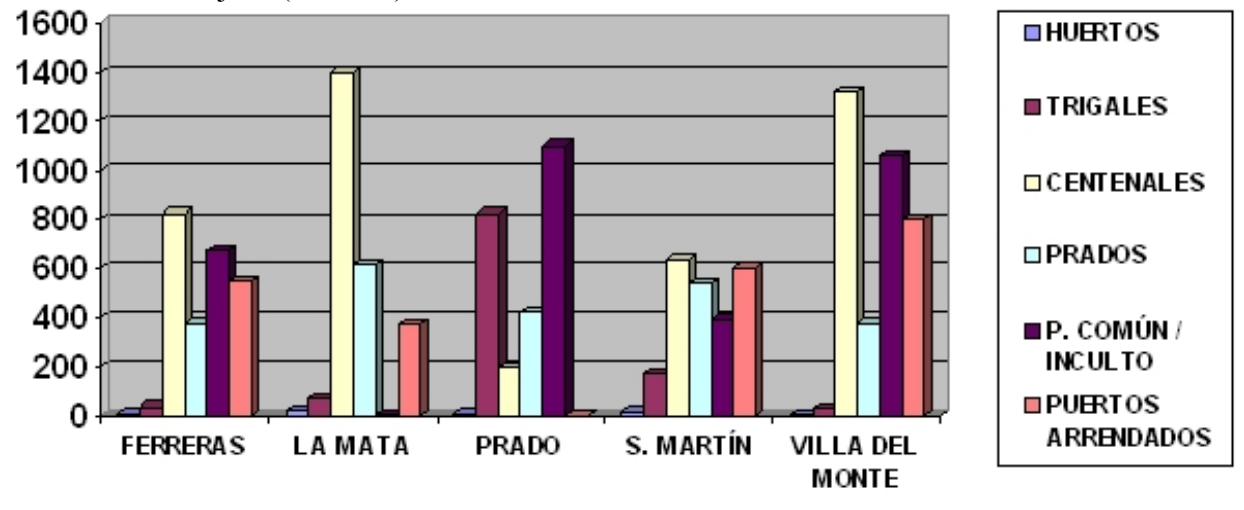

En líneas generales se puede decir, por tanto, que dado lo limitado del espacio agrícola y las no demasiado amplias posibilidades de generar riqueza por esta vía ${ }^{6}$, será el sector ganadero el que deba cubrir, en parte, dichas carencias, bien como fuerza de trabajo, bien como producto exportable hacia las tierras llanas. Pero tanto el sostenimiento de esta cabaña ganadera como el desarrollo de la actividad agrícola cerealera de secano habrá de hacerse mediante la utilización conjunta que hace la comunidad de los espacios roturados, tanto en usufructo particular como colectivo. Será, pues, en estas comunidades de alta y media montaña, como es el caso que nos ocupa, donde se van a desarrollar las mejores manifestaciones de autogestión colectiva y comunitaria, aunque sobre unas condiciones económicas precarias y un medio no demasiado favorable para el desarrollo de prácticas individuales.

\section{La organización política y administrativa}

Tanto en la Montaña Occidental, como en la Oriental, las comunidades rurales estuvieron siempre concentradas y agrupadas en amplios concejos sobre los que se organizaban política y económicamente cada una de las comunidades mediante un sistema de colectivización de los recursos y de autogobierno. En este sentido, se puede apuntar que durante la Edad Moderna el sistema concejil mantuvo los

\footnotetext{
${ }^{6}$ No se debe olvidar la necesidad de dejar el terreno dedicado al cultivo de cereales en barbecho durante un año, siendo necesaria la utilización de una amplia superficie labradía con objeto de dejar la mitad en reposo. Rubio PéRez, L. M. (1987). La Bañeza y su tierra, 1650-1850. Un modelo de sociedad rural leonesa. (Los hombres, los recursos y los comportamientos sociales). León: Universidad de León, pp. 271-272.
} 
mismos niveles de independencia y de autogestión que heredó de la Edad Media y, a pesar de la presencia del poder señorial, consiguieron mantener la operatividad de sus organizaciones concejiles y de sus órganos de gobierno ${ }^{7}$. Estas prácticas de autogestión y de participación comunitaria están directamente conectadas con la presencia y arraigo de un Derecho Consuetudinario que en sus orígenes va más allá de la Edad Media y se asienta en los Fueros altomedievales y en los "concilium" o asambleas por las que se dirigen las comunidades campesinas ${ }^{8}$.

La mayor parte de las comunidades de aldea sobre las que se instaura el señorío jurisdiccional lograron mantener el autogobierno a través del sistema concejil, lo que ocurrió especialmente en aquellas zonas que, como en el caso de la Montaña, contaban con unas comunidades más organizadas, más autónomas y con mayores recursos económicos comunitarios. No obstante, esto no impidió que la nobleza, siguiendo el modelo regio, se constituyera como un nuevo poder local a través del control de la Jurisdicción Ordinaria y de su aplicación mediante los correspondientes corregidores, jueces o alcaldes nombrados por ella misma. En el caso concreto del concejo de Valdetuéjar, observamos que se trata de un señorío cuyo titular es el Marqués de Prado, "por cuya razón no le pagan derechos algunos". . En Renedo de Valdetuéjar, nos encontramos con que la justicia es ejercida por un corregidor nombrado por el propio marqués, mientras que en el resto de pueblos es practicada por jueces ordinarios escogidos por el mismo señor. En lo que respecta a los oficios concejiles, carecen éstos de titularidad ya que son

${ }^{7}$ Rubio PÉRez, L. M. (1993). El sistema político... Op. cit., p. 47. En este sentido, se puede afirmar que apenas se aprecian diferencias entre los concejos considerados realengos o los de señorío, lo cual viene a reducir la importancia del señorío jurisdiccional, en tanto que cada lugar o aldea funcionó mediante organizaciones concejiles locales que regulaban y administraban los recursos situados en el término de cada lugar.

${ }^{8}$ Rubio PÉRez, L. M. (1993). El sistema político... Op. cit., pp. 48 y 49. El origen de estos concejos parece estar en las asambleas populares o "concilium" cuyo objetivo era la regulación de la vida de la comunidad en el siglo X. El concilium funcionó como un organismo de gobierno y justicia sobre un territorio concreto y en el caso que nos ocupa se inserta en el proceso repoblador por el que las comunidades fueron formándose por individuos que, una vez asentados en el territorio y delimitado el espacio controlado o término, iniciaban el ordenamiento de los recursos desde la presencia de la propiedad individual mediante los lazos familiares nucleares y desde el control y colectivización de los recursos comunales. Surge así y se consolida una "asociación económica agraria como mezcla de la propiedad comunal e individual de la tierra".

${ }^{9}$ Archivo Histórico Provincial de León (en adelante A.H.P.L.), Respuestas Generales del Catastro de Ensenada. 
nombrados por los concejos o por delegación de éstos ${ }^{10}$. Su duración es anual y se eligen en ciertos días del año "desde tiempo inmemorial" .

El funcionamiento del sistema de concejo abierto de vecinos es prácticamente idéntico en el conjunto de las aldeas leonesas al estar regulado bien por la "tradición", o derecho no escrito, bien por las ordenanzas concejiles. "A son de campaña tañida" tenían todos los vecinos la obligación de acudir a todas las reuniones de concejo convocadas por los oficiales, alcaldes o regidores, e incluso por cualquier vecino que tuviera que plantear una cuestión de interés para la comunidad $^{12}$. La obligatoriedad de asistencia para los vecinos queda recogida y reflejada en el ordenamiento concejil y la ausencia sin causa justificada castigada

${ }^{10}$ En el texto de Prado de la Guzpeña, cap. 2, se indica: "Iten declararon por costumbre que se ha guardado y debe observar que los regidores que salen y cumplen (...), han de nombrar dos hombres de buena conciencia y desapasionados, que acompañados de ellos hagan nueva elección y nombramiento de regidores en personas capaces y beneméritos de semejantes empleos". A.H.P.L., caja 11.246.

${ }^{11}$ Así, por ejemplo en la Villa del Monte se dice en el primer capítulo de sus ordenanzas que "es costumbre usada y guardada en dicho lugar de tiempo inmemorial a esta parte que el primer domingo de marzo de cada un año, los regidores que fueren y cumplieren dicho día junten su concejo $y$ estándolo según costumbre antigua nombren otras dos personas que ejerzan los tales oficios durante un año, que se cuente desde dicho día en adelante, los cuales nombrados sean aquellos que más convenga a la república y utilidad de los pobres, y tengan obligación de aceptar dichos oficios y usarlos con todo cuidado y vigilancia". A.H.P.L., caja 11.251. Lo mismo ocurre en la villa de Prado, cap. 1: "Primeramente declararon haber sido y ser costumbre que se debe guardar y observar que los regidores que ahora son y en adelante fueren en dicha villa, tengan obligación a hacer nueva sesión y nombramiento de estos empleos el primer domingo de marzo de cada un año que rijan y gobiernen con toda actividad". Por otra parte, en las ordenanzas de La Mata de Monteagudo se indica que "es costumbre y que se debe observar que el primer dia del año se junte el concejo y se nombren regidores nuevamente, que ejerzan este oficio durante el año, los cuales han de ser a satisfacción del concejo y regidores que salen". A.H.P.L., caja 11.246.

12

Generalmente las reuniones concejiles son convocadas por los oficiales de concejo y su frecuencia viene marcada por la normativa concejil y por la propia dinámica organizativa que exige la fijación de unas fechas determinadas y una temporalidad ajustada al año agrícola. RUBIo PÉREZ, L. M. (1993). El sistema político... Op. cit., p. 54. El capítulo 2 de la Villa del Monte indica que "los dichos regidores tengan obligación a juntar a concejo todos los lunes de cada semana para dar cuenta a los demás vecinos de las penas y negocios concejiles que hubiere que hacer, y que los dichos regidores que son y en adelante fueren cada mes tengan obligación a dar cuenta de la tala y cuentas de concejo, y pasado dicho día lunes no habiendo juntado a concejo después no lo puedan hacer, y habiéndole hecho y despedidole no puedan castigar ninguna prenda que no se hubiere manifestado en él salvo si fuere de corte y el vecino a quien tocare la guarda tenga obligación a manifestarlas dicho día lunes a los dichos regidores y no lo haciendo pague de pena dos azumbres de vino por cada vez que faltare a esta obligación y acuerdo". 
con penas pecuniarias ${ }^{13}$. Pero esta participación en las asambleas concejiles, y por consiguiente en los oficios de concejo quedaba restringida a los hombres cabezas de familia y a los vecinos, dado que uno de los cometidos fundamentales del concejo era la administración de los recursos comunales y el gobierno de unas sociedades en las que el título de vecino servía no sólo para disfrutar de una serie de derechos y obligaciones, sino para contraponerlo al de forastero, considerado éste como un competidor y como un elemento extraño a la comunidad. Por otra parte y según se desprende de la legislación concejil, las reuniones de la comunidad en concejo debían ser con frecuencia un tanto tensas, a juzgar por el articulado ${ }^{14}$, lo que llevaba a castigar con dureza cualquier discusión o altercado a la vez que se

13 En el articulado de la Villa del Monte, cap. 1 se dice que "el que faltare al dicho nombramiento (de regidores) pague de pena dos azumbres de vino salvo el que estuviere ausente en Tierra de Campos o en otras partes ajustando haberse ido ocho días antes del tal nombramiento no pague nada, ni el que faltare a él estando enfermo, preso, o con otro legítimo impedimento". Más adelante, en el cap. 30 se añade "que los días de nombramiento de regidores y oficiales que se hace en cada un año por el primer domingo de marzo y día de San Justo y Pastor deban de asistir a él todos los vecinos sin faltar ninguno y si alguno faltare pague de pena dos azumbres de vino menos que se halle con los impedimentos que en otro capitulo de estas ordenanzas van declarados". En Prado, capítulo 3, se declara que "para elegir y nombrar dichos regidores deban estar y estén al nombramiento ante todo el concejo y vecinos de dicha villa, y el que faltare, pague la pena de una cántara de vino".

${ }^{14}$ En el lugar de San Martín de Valdetuéjar, (A.H.P.L., caja 11.251), cap. 27 se recoge "que en tocando el regidor a concejo dentro de media hora acudan todos los vecinos que estuvieren en el lugar pena de medio real, y estando juntos los vecinos en el sitio que eligieren los regidores ningún vecino se altere ni levante la voz, sino que de su asiento diga a voz baja, modesta e inteligible lo que tuviere que decir y proponer, y habiéndole los regidores mandado se aquiete y hable con modestia y no lo haciendo pague de pena dos reales por la primera vez y si fuere contumaz en dar voces inquietando al concejo pague a rebeldía la pena doblada, y si alguno echase algún voto a Cristo o algún otro juramento grave sea castigado en cuatro reales por cada vez, y si un vecino a otro le tratare mal de palabra injuriosa sea castigado en otros reales". En la Villa del Monte, capítulo 4, se nos hace saber "que estando en concejo ningún vecino sea osado de levantarse de su asiento contra otro, y si lo hiciere y hablare mal de palabra y jurare el nombre de Dios u otro cualquiera juramento pague de pena dos azumbres de vino por la primera vez, y después el regidor le aperciba que no jure ni hable alto ni se quite de su asiento para ello y si lo hiciere pague de pena el doble cada uno de los reos que contravinieren a este capitulo". En La Mata, capítulo 18: "Iten declararon por costumbre usada y guardada y que se debe guardar que ningún vecino sea osado estando en concejo a alborotarle con voces altas ni desmentirse unos a otros, ni tratar en deslindar linajes y el que lo hiciere pague de pena por desmentir media cántara de vino por cada vez que lo hiciere y por lo demás a dos azumbres". En Prado, capítulo 19: "Iten declararon por costumbre antigua y que se debe observar que el que hablare descompuestamente en concejo o ultrajare a algún vecino, pague una azumbre de vino de pena y el doble si sucediere con él y regidores". 
pedía respeto y urbanidad para los regidores tanto dentro como fuera de las sesiones $^{15}$.

El carácter participativo de la comunidad en las asambleas concejiles quedaba limitado de forma exclusiva a los hombres vecinos cabezas de casa, sin que pudieran optar a él solteros, mozos o mujeres, lo que sin duda, discriminaba a una parte de la comunidad toda vez que, dadas las altas tasas de mortalidad, el colectivo de viudas y huérfanos mayores de edad podía ser un componente importante y, por lo general, el menos favorecido. Resulta curioso el hecho de que aunque como se aprecia sobre todo en las sociedades de montaña y otras forzadas a complementar la agricultura con sectores como la arriería o la trashumancia, la mujer, ante las frecuentes ausencias del varón, a pesar de que juega un importante papel socioeconómico, no es aceptada por la comunidad para representar a su marido, por lo que queda relegada a participar en las decisiones del concejo en tanto que las ausencias de los varones, solamente permitidas mediante causas justificadas, no impiden que el resto de los vecinos que forman la comunidad pueda, conforme a las normas de concejo, convocarlo y tomar las decisiones pertinentes ${ }^{16}$.

El marco de acción y cometido de las asambleas concejiles en las comunidades de aldea es muy amplio y va desde la aprobación y nombramiento de los cargos concejiles hasta la regulación de todos los ámbitos de la vida de la comunidad, tal y como tendremos ocasión de ver para el caso de los cinco pueblos citados pertenecientes al concejo de Valdetuéjar.

\section{LAS ORDENANZAS CONCEJILES}

\section{Origen y evolución}

Anteriormente señalamos que hablar de ordenanzas concejiles en el marco de las comunidades de aldea leonesas nos conecta directamente con el denominado

15 El capítulo 28 de las ordenanzas de S. Martín de Valdetuéjar nos informan de que "en el concejo y ayuntamiento se guarde el decoro a justicia y regimiento con el lugar más decente, y después sigan los más ancianos en su asiento, de manera que tengan preeminencia y separación de los ancianos a los modernos, y en el voto y proposición que se ofrezca se atienda al anciano primero $y$ después los modernos den el suyo, y se tome el más saludable y útil para el bien común". El capítulo 10 de La Mata añade: que "a los regidores que se nombraren en dicho lugar se les ha de tratar con toda la urbanidad y cortesía, y darles sin resistencia las prendas que pidieren y el vecino que lo contrario hiciere pague de pena para el concejo media cántara de vino, y si alguno encubriere pena forastera y no la manifestase aunque sea en cualquier tiempo, pague la pena que debia el delincuente y otro tanto más".

${ }^{16}$ Rubio PÉREZ, L. M. (1993). El sistema político... Op. cit., pp. 54 y 55. 
Derecho Consuetudinario, y su progresiva imposición medieval. De esta manera hay que admitir que fue el Derecho Consuetudinario leonés, la tradición no escrita, un importante marco de referencia en las relaciones socio-comunitarias de las comunidades rurales leonesas a lo largo de la Edad Moderna ${ }^{17}$.

Una vez superada la crisis política de los primeros años del siglo XVI, las sociedades de aldea leonesas inician un proceso de afianzamiento que se manifiesta en la adopción por parte de éstas de medidas que les llevarán a fijar sus términos espaciales de dominio a fin de administrar sus recursos frente a la posible capacidad enajenadora de la nobleza señorial y de las otras comunidades foráneas, lo cual se llevará a cabo a través de su organización concejil. Sin duda todos estos factores forzaron en parte a estas comunidades y a sus organizaciones locales a dotarse de unas reglamentaciones internas que emanadas del concejo y una vez aprobadas por el poder jurisdiccional nobiliario y real sirvieran no sólo para el mejor funcionamiento interno de la comunidad, sino para defenderse de ingerencias externas que podían atentar contra sus recursos o medios de producción y contra la independencia del poder local.

Pero, aunque esto pudo ser un factor que forzó a las comunidades a plasmar en letra su derecho antiguo por vez primera en el siglo XVI, conforme nos adentramos en los tiempos modernos, otras razones parecen animar a dicha elaboración escrita, razones que emanan de la propia dinámica social, y como ellos reconocen en el siglo XVIII, de la necesidad de derogar viejas normas no ajustadas a los nuevos tiempos y, sobre todo, de la parcial interpretación que cada individuo hace de la norma ${ }^{18}$, lo que obliga a escribirlas, con el objeto de que sirvan "para el buen gobierno de la comunidad y defensa de los intereses de sus vecinos" ${ }^{\text {"19 }}$. En el caso

17 IBIDEM, pp. 70-71. Las sociedades leonesas de Antiguo Régimen tuvieron en el Derecho Consuetudinario un marco de referencia para justificar sus esquemas organizativos. El recurso a la tradición como algo útil en el presente en tanto en cuanto había servido para el buen funcionamiento y desarrollo de las comunidades formadas por sus antepasados es algo tan arraigado que impregna toda la cultura campesina leonesa en la Edad Moderna y sobrepasa, con creces, las barreras contemporáneas.

18 Así, los textos que analizamos en el presente artículo recogen previamente al articulado los motivos por los que se considera de utilidad y conveniencia el que se hagan capítulos de ordenanzas de las costumbres que se deben guardar y observar, coincidiendo en todos ellos la razón de "evitar pleitos, disensiones y excusar gastos que de lo contrario se pueden seguir".

19 Apoyados en la información de los protocolos notariales se puede afirmar que es en los momentos de crecimiento del siglo XVI cuando las comunidades concejiles se dotan de su propia reglamentación escrita, lo que va a servir posteriormente de base para un segundo momento en el que, bien por estar las antiguas en mal estado, bien por carecer de ellas, otro conjunto de comunidades deciden dotarse de dichas ordenanzas coincidiendo con la fase de recuperación, una vez superada la 
concreto del Concejo de Valdetuéjar, observamos que las ordenanzas concejiles son plasmadas en papel en un momento muy concreto, finales de la segunda década del XVIII y comienzos de la tercera, "en ejecución y cumplimiento de lo mandado por autos de buen gobierno y por los jueces, residencia y justicia", tal y como se nos dice ${ }^{20}$.

\section{Significado}

Las ordenanzas nos muestran la presencia de sistemas organizativos colectivizadores que son buena muestra de la convicción de las comunidades de aldea de que solamente a través de la unión y de la pérdida de individualidad se pueden superar las rivalidades internas y las constantes presiones externas producidas por grupos de poder ajenos a la comunidad. Tanto la presencia, sobre todo en las zonas de montaña, de unidades territoriales administrativas denominadas Hermandades y Concejos, como el predominio de amplios espacios comunales compartidos y no asignados a una comunidad determinada obligaba a estas comunidades a imponerse sistemas colectivizadores y órganos de gobierno conjunto que desde la propia organización concejil local y a través de una amplia representación no sólo tiende a mejorar los aprovechamientos y la administración, sino a defenderlos de intereses foráneos ${ }^{21}$.

Estas normas consuetudinarias surgen de las propias comunidades que las elaboran de forma consensuada y no impuesta por la fuerza. Por lo menos durante la Edad Moderna, la elaboración de las ordenanzas concejiles y su posterior aprobación por el concejo se hacía generalmente desde lo que hoy conocemos como asentimiento unánime de los vecinos ${ }^{22}$. Además, parece claro que en el seno

crisis demográfica y económica de la primera mitad del siglo XVII. Sobre una nueva base institucional, las ordenanzas concejiles que aparecen durante esta centuria son una mera restauración de las antiguas, aunque es frecuente la introducción de nuevos capítulos y la derogación de otros que, o bien quedaron desfasados principalmente en la cuantía de las penas, o bien conviene ampliar nuevamente a fin de establecer nuevos intereses que, incluso pueden ser de carácter demográfico. RuBio PéreZ, L. M. (1993). El sistema politico... Op. cit., p. 71.

${ }^{20}$ Así, en Ferreras del Puerto nos movemos entre 1713 y 1725; en La Mata, 3 de marzo de 1719; en Prado de la Guzpeña, 1719; en San Martín, 25 de abril de 1722; y en la Villa del Monte, 3 de mayo de 1722.

${ }^{21}$ Rubio PÉrez, L. M. (1993). El sistema politico... Op. cit., p. 67-70.

${ }^{22}$ Tal y como se reitera en cada una de las ordenanzas: "dijeron que en ejecución y cumplimiento de lo mandado por autos de buen gobierno y por los jueces, residencia y justicia, han tomado en dicho lugar y demás de dicha jurisdicción y considerando les es de útil y conveniencia se hagan capitulos de ordenanza de las costumbres que se deben guardar y observar en dicho lugar (...) habiéndose ajuntado en su concejo y ayuntamiento la mayor parte de los vecinos de él, ordenaron, 
de estas sociedades el Derecho solamente incide en el individuo en tanto que es miembro o vecino de una comunidad determinada, encerrando por tanto, un "carácter asociacional" 23 .

\section{Articulado}

La práctica totalidad de las Ordenanzas Concejiles se apoyan en dos aspectos fundamentales: el espíritu colectivista o colectivizador que domina todos los ámbitos comunitarios, llegando a anular en buena medida al individuo, y la idea de que el desarrollo de cada miembro de la comunidad solamente puede realizarse en el contexto hegemónico de ésta ${ }^{24}$. Directamente relacionado con esto se hallan los altos niveles de solidaridad social que se imponen las comunidades a través de la organización concejil y que tienden a garantizar a cada uno de sus miembros el apoyo económico o espiritual de la colectividad ${ }^{25}$.

A continuación procederemos al análisis de los distintos artículos de las ordenanzas concejiles de los cinco pueblos ya conocidos, cuyo número y temática es la siguiente:

dispusieron y nombraron, para que ejecuten dichas ordenanzas y decidiesen sus capitulos a (...), sus vecinos y mediante hoy se hallan en presencia de su merced para este efecto, le pidieron y suplicaron por sí y en nombre de los demás sus vecinos, reciba de los susodichos juramento en la forma ordinaria para que debajo de él ejecuten dicha ordenanza y declaren dichas costumbres (...), los cuales entendidos de este caso prometieron haberlo asi".

23 Posiblemente fuese este arraigo junto a la importancia adquirida por este sistema en el desarrollo de la sociedad rural leonesa lo que motivó que su mantenimiento desde la Alta Edad Media hasta el siglo XX se produjese sin grandes cambios y modificaciones, a pesar de ser atacado de forma más o menos directa en dos momentos claves del proceso histórico nacional: durante la Baja Edad Media con el nuevo sistema de Regimiento y la consolidación del Señorío Jurisdiccional y durante el Liberalismo del siglo XIX. RuBio PÉreZ, L. M. (1993). El sistema político... Op. cit., p. 72.

24 Desde la consideración de que estas sociedades se habían autosometido a un sistema organizativo en el que lo colectivo parece imponerse a lo individual, en el que familia y comunidad están por encima del individuo, se comprende que cada comunidad fuerce a sus componentes a unos niveles de sometimiento y solidaridad que únicamente se justifican en función de una concepción colectivista o comunitarista y ante el convencimiento de que solamente a través de esta acción conjunta la comunidad puede enfrentarse a lo foráneo y desarrollar sus intereses privados bajo la tutela de la propia comunidad. RuBio PÉREZ, L. M. (1993). El sistema político... Op. cit., p. 83.

${ }^{25}$ IBIDEM, p. 89. Analizando los artículos de las ordenanzas, se puede concluir que su aplicación estaba directamente conectada a unas sociedades con un alto grado de autorregulación y en las que el pequeño campesino propietario además de ser dominante necesita la protección de la comunidad para subsistir y para desarrollar el sistema productivo. 
Cuadro 3. Temática de las ordenanzas concejiles del Concejo de Valdetuéjar

\begin{tabular}{|c|c|c|c|c|c|c|c|c|}
\hline & \multirow[b]{2}{*}{ A } & \multicolumn{3}{|c|}{ B } & \multirow[b]{2}{*}{$\mathrm{C}$} & \multirow[b]{2}{*}{$\mathrm{D}$} & \multirow[b]{2}{*}{ E } & \multirow[b]{2}{*}{$\mathrm{F}$} \\
\hline & & B1 & B2 & B3 & & & & \\
\hline Ferreras $^{26}$ & & & 1 & & & 1 & & 2 \\
\hline La Mata & $5^{27}$ & 3 & 9 & 1 & & 1 & & 19 \\
\hline Prado & 5 & 9 & 25 & 6 & & 1 & 5 & 51 \\
\hline S. Martín & 3 & 3 & 20 & 3 & 2 & 1 & 4 & 36 \\
\hline Villa del Monte & 9 & 3 & 20 & 2 & 4 & 1 & & 39 \\
\hline
\end{tabular}

A, Gobierno local; B, Actividades económicas B1, Agricultura; B2, Ganadería; B3, Comercio); C, Vida cotidiana; D, Vecindad; E, Trabajos colectivos; F, Total

Como vemos en la tabla anterior, resulta abrumador el número de capítulos que atañen sobre los aspectos de la ganadería, puesto que en la Montaña leonesa el predominio de espacios no roturados y aprovechados en régimen comunal, junto a la propia orografía, ofrecen las mejores condiciones para el desarrollo de este sector frente a la agricultura. Ciertamente, en las comunidades ganaderas la preponderancia de los espacios comunales y el propio medio hacen que el desarrollo de la agricultura se ciña a unos espacios limitados, localizados en los valles y en clara pugna con los prados de "pelo y otoño", por lo que la actividad legisladora concejil tiene menor incidencia, centrándose fundamentalmente en la obligatoriedad que se impone desde el concejo a fin de que todos los vecinos

${ }^{26}$ Para este pueblo hemos hallado únicamente el capítulo referente a las condiciones para adquirir la vecindad (28 de abril de 1713) A.H.P.L., caja 11.245; así como la derogación del capítulo cuarto de sus ordenanzas (24 de marzo de 1725) y el establecimiento de otro nuevo en sustitución de éste (A.H.P.L., caja 11.254. Dicho capítulo había sido redactado en 1717, tal vez junto con el resto de las costumbres del lugar, y nos habla acerca de "que cada vecino del referido lugar de Ferreras pudiese traer en el coto boyal de él cuatro cabezas de ganado mayor de tres años arriba libremente, con otras declaraciones que en él se expresan".

${ }^{27}$ Aquí se incluye un capítulo que alude a la elección del mayordomo del santuario de la Nuestra Señora de la Velilla, situado en término de dicho lugar y con gran devoción entre los pueblos de las inmediaciones. Tal hecho es corroborado al consultar las partidas testamentales de los núcleos próximos, devoción que cruza incluso los límites de la provincia leonesa y se remonta, al menos, a la primera mitad del siglo XVII. Ejemplo de lo anterior es el testamento de Catalina Reguera, vecina del pueblo palentino de Cardaño de Arriba que había fallecido el 10 de diciembre de 1643, quien en su testamento deja estipulado que se digan por su ánima 6 misas rezadas en el monasterio de Nuestra Señora de La Velilla. Archivo Histórico Provincial de Palencia (A.H.P.P.), caja 16. 
tengan y cultiven "huerto y naval ${ }^{28 ",}$, con objeto de garantizar el sustento de sus miembros y evitar robos y otros daños ${ }^{29}$.

Por otra parte, aquellos espacios privados dedicados a prados, linares o cereal, demandaban la regulación del agua como elemento fundamental para producir. Al respecto, el ordenamiento concejil es bastante escueto, lo que puede indicar el débil desarrollo de la agricultura regadía, y se limita a fijar las acciones comunitarias sobre las presas, canales y la reparación de éstos en ciertos momentos del años, llegando muchas veces a delimitar derechos en determinadas fincas pertenecientes a forasteros ${ }^{30}$.

${ }^{28}$ Donde mejor se refleja la fuerza de la organización concejil en su acción sobre los medios de producción, así como la importancia de ésta para unas sociedades ganaderas de montaña, es en el tema de los huertos o "nabales" u otras superficies de forzado laboreo para los vecinos. RUBIO PÉREZ, L. M. (1993). El sistema político... Op. cit., p. 110.

${ }^{29}$ Así, en La Mata, cap. 2: "Iten ordenaron y declararon por costumbre usada y guardada que se debe guardar y observar que todos los vecinos que al presente hay y hubiere en adelante en dicho lugar, haya de tener cada uno su huerto para berzas, nabos u otro género de legumbres para el sustento de sus familias, $y$ en los tiempos que cada cosa requiere, y el vecino que no le hubiere pague de pena seis reales en cada un año al concejo, y al doble el que pudiere tenerle y no le tuviere, y se advierte que si se hallase ver entrar o salir alguna persona, grande o pequeña, en dichos huertos, siendo vecino o natural de dicho lugar, pague de pena por cada entrada media cántara de vino para el concejo y sus gastos, y al doble a rebeldía". En Prado, cap. 25: "Iten declararon por costumbre que se debe observar de todos los vecinos de dicha villa, hayan de tener y tengan huerto para berzas $y$ verduras, y el que no quisiere y no lo tuviere, pague de pena media cántara de vino". En San Martín, cap. 7: "Iten acordaron y ordenaron que cada vecino siembre cada año legumbres como mejor y más pudiere y asimismo tenga huerto de berzas para el abasto de su casa y familia para que con eso se eviten de robarse unos a otros, y el que no lo hiciere pague de pena cuatro reales, que el que no tuviere heredad o linar a propósito no se le pueda obligar, pero si algún vecino se la quisiere dar esté obligado a sembrar como dicho es, y la misma pena pague cualquiera persona que entrare a coger legumbres o berzas en huerto o tital ajeno, y esto por la primera vez y a la segunda doblado". En la Villa del Monte, cap. 33: "Iten ordenaron que cada vecino para conservación de su casa y sustento de su casa haya de tener huerto y naval para sembrar todo género de legumbres pena de una cántara de vino al que no le tuviere guardándosele su derecho a cada uno que le tuviere mandando lo que convenga contra el que no les guardare y si se cogiere en él alguna persona sea de noche o de día se le castigue en dos reales por cada vez".

${ }^{30}$ Así por ejemplo en Prado, cap. 26: "que mediante la presa de la Vega de Abajo es de mucho provecho y utilidad a todos los interesados, vecino y pastores, los regidores que son y fueren tengan obligación de dar aviso a los forasteros que tienen prados debajo de dicha presa, que vengan a sacar el día 30 de noviembre de cada un año, para que quede buena, y el agua vaya corriente. $Y$ dicha presa se señala y ha de ir desde la calle a la Arca de Parado de la Espina, que está en frente de la Lomanilla. Y el que tuviere prados y no viniere a dicha presa para dicho día, pague la pena en esta manera. El que no estuviere en la calle al caer el sol, que es donde se comienza, ha de pagar de pena ocho maravedís. Y el que no estuviere al Prado de San Roque, dieciséis maravedis. Y el que faltare al prado, que es de préstamo de los señores de la Casa de Prado, que antiguamente llevaba Pedro de 
En zonas de montaña o en los cursos medios de los ríos, donde el denominado "otoño" cumple una importante función de reserva invernal, las organizaciones concejiles regulan la utilización de estos espacios manteniéndolos cotos durante todo el verano y hasta que sus dueños hayan recogido la segunda corta de hierba ${ }^{31}$. Además, la importancia que tienen las superficies praderías privadas para el desarrollo complementario de la ganadería queda reconocida por el ordenamiento concejil y por el hecho de que se llegue a prohibir la roturación de estos espacios sin la autorización del concejo, lo que supone un importante recorte del dominio útil de estos bienes, no así del dominio directo ${ }^{32}$.

Al igual que en otras zonas de la corona castellana, los montes abiertos concejiles y las praderías constituyen durante la Edad Moderna un importante complemento de apoyo para las economías campesinas. Uno de los cometidos básicos de las ordenanzas leonesas es la regulación y administración de estos espacios cuyo dominio pleno corresponde al concejo. Praderías, montes y sus correspondientes formas de aprovechamiento colectivo ocupan más gran parte de su articulado, lo que demuestra la importancia que tienen estos espacios para las comunidades rurales en relación con la actividad ganadera. Factores geográficos como la altitud, la limitación de las zonas agrícolas, la climatología, así como la dependencia del sector ganadero, fuerzan a estas comunidades a reglamentar y ordenar su vida en torno a estos amplios espacios de montes abiertos que en el caso de las montañas leonesas sirvieron de agostadero a los ganados mesteños ${ }^{33}$.

Villarroel, vecino que fue de esta dicha villa, pague otro medio real de pena. Y el que faltare al sitio último señalado pague dos reales". En el cap. 29 se añade: "que se dé obligación de los regidores que entraren en cada un año, de hacer tener limpias las presas para el día último del mes de abril, de este regimiento. Y si asi no lo hicieren paguen de pena media cántara de vino”.

${ }^{31}$ En la villa de Prado, cap. 12, se dice que "en cuanto al coto de la Rabeja de Francisco para abajo, hasta la presa nueva, el ganado menudo no pueda entrar desde primero de marzo hasta el día de año nuevo, primero de enero de cada un año, excepto que la nieve las agravie. Y quitada que sea, vuelvan a salir luego fuera de dicho coto y el rebaño que entrare pague de pena media cántara de vino”. En San Martín, cap. 23: "que desde el primero de marzo hasta el día de San Miguel no pueda el ganado bravio entrar ni pastar en el Coto de las Cuevas como es el Candanedo, la Cota de los Hoyos y la Cuesta de la Velilla, ni El Manzanal de las Casas, ni tampoco la cabaña de las vacas si no es que sea con acuerdo del concejo, y el rebaño de ganado menudo pague por cada pastor dos reales y lo mismo la vez de yeguas y de la cabaña".

32 Rubio Pérez, L. M. (1993). El sistema político... Op. cit., p. 102.

33 Para CABO AlONSO, A.: "Medio natural y trashumancia en la España peninsular" en RUIZ Martín, F. y García SAnZ, A. (eds.) (1998). Mesta, trashumancia y lana en la España Moderna. Barcelona: Crítica, pp. 11 y 12, los movimientos realizados con las reses responden a la dificultad de alimentar una grey importante sobre los mismos predios durante todo el año y, a la vez, a la 
La organización de los espacios privativos de cada concejo se asienta fundamentalmente en las zonas más bajas o cercanas a las poblaciones donde se levantan las dehesas o montes de roble y sobre las praderías o cotos primaverales denominadas "bueyerías", que sirven para el agostadero de los ganados mayores estantes desde la participación en los rebaños concejiles. Se trata de zonas de pasto o aprovechamiento mancomunado cuya importancia para la economía montañesa se pone de manifiesto en el celo con que guardan y regulan estos espacios los concejos desde la Edad Media, conscientes de los ataques externos y de la importancia que tienen para su desarrollo ${ }^{34}$.

Los espacios praderíos ocupan buena parte del articulado de las ordenanzas. Parece claro que es la mayor o menor conservación de estos espacios, que por lo general se sitúan cerca de las poblaciones y sobre suelos de calidad y cercanos a los ríos, lo que puede marcar las diferencias económicas y las posibilidades de unas sociedades y de otras, ya que en ellos las organizaciones concejiles tienen unos importantes recursos que administrar y parte de su razón de ser, mientras que la comunidad un medio de producción importante y una reserva con la que cubrir futuros procesos de crecimiento ${ }^{35}$.

En este sentido, el mejor exponente de la organización colectiva de los aprovechamientos comunales lo tenemos en el desarrollo del sistema colectivo denominado "veceras" de ganado mayor y menor. Los aspectos más importantes recogidos por las ordenanzas son los que hacen referencia a la distinta tipología de las veceras y al número de cabezas que cada uno de los vecinos puede apacentar en dichos pastos, lo que en buena medida limita en la práctica el número de cabezas

conveniencia de aprovechar recursos lejanos, que de otra forma, estarían inactivos o infrautilizados cuando en los de partida escasean o no existen.

${ }^{34}$ De hecho, la derogación del capítulo cuarto de las ordenanzas de Ferreras del Puerto en 1725 y su sustitución por otro nuevo se relaciona con lo dicho ya que pasamos de una situación en la que cada vecino podía traer en el coto boyal cuatro cabezas de ganado mayor de tres años arriba libremente, a otra donde se va a poder traer solamente tres reses de bueyes machos, dándose como motivo "el conocido daño y perjuicio que se les sigue de lo contenido en dicho capítulo que ha dado motivo a que se haya desecho la cabaña que se acostumbraba haber, y que cada uno para labrar sus heredades necesita cebar a prevención sus ganados a fin de que estén de sazón para ejecutarlo y no estarlo pastando con los demás por ser muchos". En Prado, cap. 13: “que en cuanto al coto boyal, que el año que estuviere cargado y sembrado el pago de arriba con el ojedo, ningún ganado pueda entrar en dicho coto hasta el día de Año Nuevo. Y lo propio se entiende el año que estuviere sembrado el coto de abajo, y la carrera y el monte hasta el día de San Miguel, pague de pena media azumbre de vino (...)".

Rubio PÉrez, L. M. (1993). El sistema político... Op. cit., p. 105. 
de ganado de tiro y lo ajusta a las necesidades de las explotaciones agrarias al permitir solamente el acceso a una o dos yuntas por cada explotación ${ }^{36}$.

Junto al aprovechamiento y organización concejil de los pastos y dehesas comunales los montes de leña adquieren entidad propia en el ordenamiento local de aquellas comunidades titulares de su dominio y usufructo. Estos espacios productivos que aún no han conocido la acción roturadora del hombre, además de soportar en buena medida el desarrollo de la cabaña ganadera aportaban a algunas comunidades de montaña la materia prima sobre la que giraba una industria complementaria artesanal que producía carbón y utensilios de labranza, de ahí que estas comunidades regulen el aprovechamiento colectivo de estos recursos y velen por su conservación y uso privativo ${ }^{37}$. A su vez, el reparto anual de leña entre todos los vecinos desde la reglamentación concejil es otro de los aspectos donde se ve la fuerza e importancia de unos concejos frente a otros que por las circunstancias

36 IBIDEM, p. 107. En estas comunidades de montaña y en otras agrícolas de las vegas, los concejos permiten la tenencia de "hatos" o rebaños particulares de ganado menor, fuera de la vecera concejil, lo que no exime a sus dueños de cuidar la vecera cuando le toque y les obligan a que su rebaño "ande detrás de la vecera de concejo". En La Mata, cap. 5: "que a cualquiera vecino que le tocasen las beceras de bueyes o vacas haya de ir con ellas el mayor de casa y el que tuviese algún hijo o criado que sea suficiente y habil cumpla, y si alguno se quejase de éstos sea por declaración de hombres y el que lo contrario hiciere pague dos azumbres de vino para el concejo". En Villa del Monte, cap. 11: "que la vecería de los bueyes, vacas, jatos, o demás ganados y demás vecerías de concejo deban ir con ellas la cabeza mayor de cada casa o la persona que fuere abonada por el concejo, y el que lo hiciere al contrario pague de pena dos azumbres de vino, y el daño que sucediere por su omisión salvo que sea vecería que tenga vaquero, que ésta corra por su cuenta, y si en un día le tocaren a un vecino dos vecerías eche la una adelante con obligación de volver después a guardar por ella debajo de la misma pena si hiciese lo contrario".

37 En La Mata, cap. 17: "Iten declararon ser vedados de corte y poda el avellano, mostajo, manzanal, cerezal, salguero y fresno y el negrillo, y las bilortas aunque sean de roble en los montes y cotos, y el que lo hiciere pague de pena por cada vez dos azumbres de vino para el concejo". En Prado, caps. 39 y 40: "Iten declararon que ninguna pueda ir ni vaya al monte coto por leña, y el que lo hiciere y trajere algún madero o rama verde, pague un real de pena por cada cosa. Iten que si alguna persaona cortare algún árbol fructífero silvestre, pague de pena media cántara de vino". En Villa del Monte, cap. 8: "que ningún vecino pueda cortar ni podar ningún árbol de roble, mostajo, margamón, salguero, ni los fructiferos en el coto de la bueyería de los bueyes, ni los árboles frutales en todo el demás término, y a la persona que se le ajustare haberlo hecho pague de pena doce reales para gastos de concejo y si alguno hubiere menester algún madero de la bueyería o monte coto se le haya de dar siendo necesario pagar por el ocho reales aplicados en la misma forma y asimismo pague media cántara de vino el vecino que se ajustare haber cortado algún madero en dicho monte coto"; y cap. 9: "que el vecino que se le ajustare haber podado o cortado velortas que el concejo tuviere cotas de cualquiera género que sean pague de pena dos arrobas de vino, cuatro azumbres para el pedidor de pena y las doce restantes aplicadas para gastos de concejo". 
estructurales ya apuntadas tienen poco que administrar y que repartir entre sus habitantes ${ }^{38}$.

En lo que respecta a la cabaña ganadera, en la montaña y zonas de transición, donde ésta se constituye como el medio fundamental y básico, parte de los derechos individuales sobre la propiedad de los animales quedaban limitados por el interés social o comunitario, sobre todo en lo referente a la elección de los mejores ejemplares destinados a sementales. Así, los concejos proponen cada año los vecinos que han de elegir los sementales para las distintas especies de ganado, prohibiéndose la castración de los ganados jóvenes hasta que sean vistos por los miembros del concejo ${ }^{39}$. Se trata, sin duda, de un importante servicio de los

${ }^{38}$ En Ferreras, en el capítulo de ordenanza de 1713 se añade: "Y porque reconocemos que los montes van de mala calidad por la mucha saca para carreterías, ordenamos asimismo que ningún vecino que es o fuere pueda hacer más que dos viajes de madera o de costanas y otro de carbón y a las viudas se les ha de comunicar la mitad, y el que contraviniere y (...) a las carreterías haya de pagar y pague al concejo diez reales por cada una”. En La Mata, cap. 16: "que ningún vecino ni habitante en dicho lugar no pueda hacer por el discurso del año más de dos carreterías de madera ni carbón, y el que lo hiciese pague seis reales por cada una de las que así echase de más". En Prado, cap. 36: "que ningún vecino pueda hacer en todo el año más de cuatro carros de cal con la leña de la villa, y el que excediere pague de pena dos cántaras de vino". En San Martín, cap. 5: "Iten que ningún vecino ni habitante pueda hacer más que cuatro carreterías cada año, la una de carbón, y las otras tres de madera y arcos, excepto que compre la madera al concejo (...)". En la Villa del Monte, caps. 31: "que en el discurso de cada un año ningún vecino pueda hacer más que tres carreterías a Campos con maderas y si hiciere más pague por cada una una cántara de vino salvo que sea ajustándosele que trae la madera de fuera parte que en tal caso cada vecino pueda hacer las que pudiere". y 38: "que cada vecino pueda hacer un par de ruedas para el manejo de su casa libremente, trayendo la madera de Montecalvo, y no las han de poder vender a ninguna persona pena de cuatro reales y si la madera fuese de coto le pueda castigar el concejo a su arbitrio".

39 En La Mata, cap. 7: "que cualquiera vecino que tuviere novillos que vayan a tres años no puedan caparles, ni hacerles las cabezas hasta que pase el nombramiento y día de buen año de cada uno, y el que hiciere lo contrario pague de pena cinco cántaras de vino para dicho concejo. $Y$ asimismo el que tuviere cerdos nacidos desde primero de marzo no los pueda vender ni capar hasta pasado el día de san Martín de cada un año, por causa de la escojeta para la multiplicación, y si se les ofreciese venderles, ha de ser avisando a los regidores y dejando el mejor de cada lechugada para dicha escofeta, y el que lo contrario hiciere pague de pena las mismas cinco cántaras de vino además de que a su cuenta se haya de comprar y compre toro y berrón a satisfacción de dicho concejo, para que se hayan uno y otro de su misterio por el tiempo que se ha acostumbrado y se acostumbra". Prado, cap. 6: "que los regidores que ahora son o fueren, tengan obligación de nombrar dos hombres que cojan toro y berrón conveniente para el bien común de dicha villa. Y si pareciere algún novillo capado el día de la escofeta, pague el dueño de quien fuere cinco cántaras de vino, y esté obligado a dar otro a satisfacción de dicho concejo. Y se entiende que el toro se ha de elegir y escoger el día de San Miguel de septiembre, y aunque su dueño diga es comprado y lo pruebe en todo tiempo y pase como si por su persona o personas de su casa fuere, le criado y apastorgado". San Martín, caps. 18: "que en cada un año por el día de San Miguel se nombre el berrón para padre 
individuos más acomodados al conjunto de la comunidad ya que esto supone la prestación temporal de un bien de producción a cambio de recibir de la comunidad el sostenimiento de dichos animales sobre los mejores pastos comunales ${ }^{40}$.

\author{
El asociacionismo solidario va más allá de los aspectos meramente económicos \\ o materiales para hacerse extensivo al ámbito de lo social ${ }^{41}$, adquiriendo una mayor
}

del ganado cerduno, y éste sirva hasta dicho día y de él hasta el primer día de marzo siguiente aunque se haya nombrado otro, y el que fuere nombrado no le pueda el dueño capar ni vender pena de cuatro reales y de buscar otro a su costa a satisfacción del concejo, y se advierte que cualquiera vecino que tuviere camada de marranos de cría desde primero día de marzo de cada un año, haya de dejar y deje el mejor marrano que tuviere de la camada, y no la pueda vender ni descabalar sin llamar primero a los regidores para que escojan el mejor para que el día susodicho del nombramiento se elija el mejor de los que se hallaren y el vecino que no cumpliere con lo susodicho y lo mismo el habitante pague la misma pena arriba dicha"; 19: "que en cada un día primero de cada año se nombre toro para padre de las vacas de la cabaña y para ello nombren dos hombres desapasionados que no tengan novillo del nombramiento y éstos elijan el que mejor les pareciere y nombrado se le ponga pena al dueño de tres mil maravedies no le cape ni rabisede ni motile, (...) y se añade a este capitulo que el novillo que se nombrase por toro no le pueda unir su dueño ni trabajar con él hasta el primer día de agosto excepto que la extrema necesidad le obligue por no tener con qué trabajar, y para ello ha de dar cuenta al concejo para que reconozcan si tiene de ello necesidad, (...) y guardando en esto la costumbre antigua que dicho toro por el discurso del año que lo fuere sea libre de guarda y toda contribución de vaquero, y además libre a su dueño de la guarda de otra vaca o novillo de la cabaña pero no de la soldada del vaquero (...)"; y 21: "que en cada un año el día de Santiago Apóstol, los regidores de dicho lugar nombren dos vecinos que elijan y nombren sementales del ganado lanar y cabrio entre todo género de ganaderos, (...) y los que fueren apenados no los capen ni vendan sus dueños y el que lo hiciere pague de pena cuatro reales y le pueda obligar el concejo al dueño a que busque a su costa otro semental a satisfacción de los hombres nombrados". En la Villa del Monte, caps 15: "que el vecino que tuviese marranos de cría haya de guardar por ellos llegando a tener diez semanas, que se han de contar desde el día de su nacimiento y el que los trajere comprados de quince días haya de guardar por ellos y el que los tuviere no los cape y en especial los que naciesen desde el día de San Juan hasta el día de San Miguel de cada un año, ni los venda sin licencia del concejo y si lo hiciere pague diez reales de pena por cada una vez que así lo hiciere y que busque padre a su cuenta y le dé de comer"; y 17: "que el vecino que tuviere novillos no los pueda capar ni vender sin licencia del concejo desde el día de Año Nuevo hasta otro día de en año, y si lo hiciere pague de pena doce reales y por su cuenta se busque toro a satisfacción del concejo y los dueños de dichos novillos no puedan meterlos a pastar en los cotos, y si lo hicieren hayan de pagar de pena lo que ordenare el concejo".

${ }^{40}$ Rubio PéRez, L. M. (1993). El sistema político... Op. cit., p. 111.

${ }^{41} \mathrm{Sin}$ embargo, frente a lo que pudiera pensarse, en estas comunidades ganaderas se aprecia un mayor individualismo en el plano meramente social que entre las comunidades agrarias ribereñas. Posiblemente sea la limitación de los medios privados y la mayor dependencia de lo comunitario lo que explique la menor presencia de manifestaciones solidarias sociales entre la vida y la muerte por parte de las comunidades ganaderas frente a unas comunidades agrícolas que diseñan un ordenamiento mucho más rico y completo en torno a los temas de carácter social. RUBIO PéREZ, L. M. (1993). El sistema político... Op. cit., pp. 89-90. 
plasmación en el plano de lo espiritual y de la muerte. En este contexto, la religión y las prácticas religiosas se realizan bajo el control del concejo, quien además de fijarlas, impone a sus miembros unas obligaciones que alcanzan su mayor expresión en las manifestaciones relacionadas con el hecho cotidiano de la muerte. Así, el fallecimiento de cada uno de los miembros de la comunidad paraliza, por decreto, la actividad productiva de ésta y obliga a sus miembros a participar en todos los actos fúnebres que se inician con la obligación de "velar al difunto" día y noche y finalizan con su entierro y los correspondientes actos religiosos ${ }^{42}$.

Por otra parte, refiriéndonos al concepto de vecino en el seno de las comunidades de aldea leonesas, hay que decir que éste adquiere una dimensión más amplia que la mera pertenencia o adscripción a una comunidad o pueblo. Es fundamentalmente un concepto que se opone al de forastero, y adquiere mayores connotaciones sociales conforme las comunidades cuentan con un poder de autogestión y control sobre sus espacios, sus recursos económicos y sus efectivos humanos más elevado. A su vez, el concepto de vecindad encierra participación, deberes y derechos. Deberes en tanto que el vecino se compromete a acatar y jurar el ordenamiento concejil o las normas consuetudinarias y, por consiguiente, a organizar su vida familiar, dado que vecindad plena está ligada a matrimonio y familia, bajo los esquemas comunitarios entre los que la contribución personal y económica a las cargas y actividades colectivas es un punto básico. Derechos porque a cambio la comunidad le hace partícipe de su gestión y de la utilización de los recursos económicos comunitarios, a la vez que garantiza sus derechos individuales ${ }^{43}$.

${ }^{42}$ En la Villa del Monte, cap. 34: "que el día y cuando que sucediere haber algún cuerpo difunto en este dicho lugar de alguna persona de edad de siete años para arriba que todos los vecinos del dicho lugar y sus mujeres o por lo menos dos personas de las mayores de cada casa sean obligados a asistir al entierro del dicho difunto o difunta mayor de siete años. Y estando presentes todos los susodichos a sacar dicho cuerpo de su casa y a acompañarle cuando le lleven para la iglesia y asistir a los oficios y misa del entierro que se dijeren por el ánima de dicho difunto o difunta, y que este capitulo desde hoy en adelante por ser obra de misericordia y tan del servicio de Dios Nuestro Señor, y de tanta caridad y socorro de las Benditas Ánimas del Purgatorio, inviolablemente se guarde y cumpla en la forma referida pena de cuatro reales que ha de pagar cada una de las personas arriba dichas que faltare a lo susodicho o parte de ello desde sacar el cuerpo de su casa hasta darle tierra y cantarle el responso, los cuales dichos cuatro reales de pena van aplicados desde ahora en esta manera: dos reales para la limosna de una misa rezada por el ánima del dicho difunto o difunta, y los otros reales para luz de la lámpara del Santísimo Sacramento de esta iglesia, la cual dicha pena tengan obligación de ejecutar y cobrar los regidores que al presente son y fueren y a entregarla al señor cura y mayordomo de dicho lugar para que la distribuyan y cumplan en la forma arriba dicha con toda brevedad".

${ }^{43}$ Pérez Álvarez, M. J. (1996). La montaña..., Op. cit., pp. 56-59. 
Tanto en el Derecho Consuetudinario como en el ordenamiento escrito el articulado referente a la normativa que atañe a los vecinos tiene un destacado papel y toca tres situaciones fundamentales: los hijos de vecinos casados en el mismo lugar, los vecinos e hijos de éstos que toman cónyuge fuera del lugar y aquellos forasteros que pretenden avecindarse en la comunidad ${ }^{44}$. El origen de estas prácticas hunde sus raíces en la Edad Media y ponen de manifiesto el férreo control que buena parte de las comunidades leonesas tiene sobre su vecindario en sintonía con las leyes del reino y con las estructuras dominantes. En este contexto y durante

${ }^{44}$ Estas tres situaciones son tratadas con detalle en cada una de las ordenanzas. Así, por ejemplo, en La Mata de Monteagudo, capítulo 8: "que cualquiera hijo de vecino que lo pidiere y lo quisiese ser en dicho lugar de La Mata haya de dar y de a cada vecino una libra de carnero o castrón y una azumbre de vino y el pan necesario para una comida, uno y otro a satisfacción de los regidores que son o fueren de dicho lugar. Y asimismo declararon que cualquiera otra persona forastera que se casare con hija de vecino y pidiere la vecindad, se le de con tal que primero y ante todas cosas haya de calificar su vecindad y ser hijodalgo o notorio reconocido por tal en Junta General de los seis lugares de que se compone este Concejo de Valdetuéjar, y además haya de dar y de por la entrada ducientos reales y una comida a los vecinos, de libra y media de carnero, azumbre y medio de vino y el pan necesario a cada vecino. Y si marido y mujer fuesen ambos forasteros pague la comida y el dinero al doble desde hoy arriba, con advertencia que el pan, vino y carne que se gastare en dicha comida ha de ser de la obligación de los regidores que a la sazón fueren de dicho lugar en nombre de los vecinos, para que en su compañia vayan y vean y voten dicha comida y reconozcan si se puede gastar y manifiesten al concejo (...)”. En San Martín, capítulo 1: “que cualquiera persona que viniere de otro lugar a ser vecino en este de San Martín, siendo marido y mujer ambos de fuera, y no siendo uno $u$ otro hijo de vecino de este dicho lugar, hayan de dar y pagar por la vecindad ciento y diez reales de vellón y además de esto haya de dar una comida a todos los vecinos en esta manera, a libra de carne, un pan de a dos libras y media, una azumbre de vino a cada vecino, y además su taza de caldo, su platillo de menudo, y otro de verdura o legumbre conforme el tiempo, y si fuere Cuaresma se dispondrá a la voluntad del concejo. Y en cuanto a los que fueren hijos de vecino, se entienda que si algún forastero casase con hija de vecino o el hijo de vecino casase con forastera, sólo pagan por razón de vecindad veintidós reales de vellón, y la comida en la manera susodicha, y se advierte y queda por capitulo de ordenanza que si algún vecino de este dicho lugar por algún motivo o causa que le sobrevenga se saliese de vecino o se avecindare y fuese a otro lugar, y después se volviese a vivir a éste, y quiere ser otra vez vecino en él, pague los dichos ciento y diez reales y la comida y uno $y$ otro lo hayan de dar antes que sean admitidos por vecinos, y si se les concediese algunas treguas, ha de ser con beneplácito y acuerdo de todo el concejo, y en esta manera y no en otra sean admitidos". En la Villa del Monte, capítulo 14: "que cualquiera hijo de vecino que quisiere avecindarse en dicho lugar haya de dar y pagar por su entrada a cada un vecino a azumbre de vino, una libra de carne y el pan que fuere necesario para la comida y que se ha de dar bien aderezada y compuesta, con obligación de llamar los regidores a su casa para que vean y reconozcan la carne y se pese para echarla a cocer. Y siendo forastero el que quisiere dar su vecindad además de haberle de dar lo arriba dicho haya de pagar cien reales de vellón y con obligación de echar de beber por un año en concejo, y de otra forma no sea admitido por tal vecino". Finalmente, en Prado de la Guzpeña, capítulo 45: "si algún hijo de vecino o hija quisiere serlo, haya de pagar y pague la comida acostumbrada a satisfacción de los regidores y vecinos. Y el que no fuere hijo o hija de vecino, haya de dar dicha comida y pagar seis ducados al concejo de dicha villa". 
la Edad Moderna cualquier variación en la condición civil del individuo incumbía a la comunidad al afectarle a ésta de forma indirecta. El hecho de tomar estado matrimonial obligaba a los individuos a someterse a las reglas de la familia, pero también a las de la comunidad en la que vive, así como a hacer partícipe a ésta de los correspondientes "estipendios". Tales prácticas parecen extendidas entre el conjunto de comunidades de aldea leonesas, y a partir del siglo XVIII se amplían y son utilizadas por las comunidades con otros fines como el control demográfico y la búsqueda del equilibrio recursos-población, e incluso en lo referente al equilibrio demográfico y social interno ${ }^{45}$.

Así pues, las comunidades de montaña parecen conscientes de sus limitaciones y de su total dependencia de los recursos comunitarios. A la vez, cuentan con la suficiente organización como para autorregularse y legislar al respecto. De esta manera, la necesidad de controlar el número de vecinos es justificada mediante razones de distinta naturaleza que van desde las de carácter social e ideológico hasta las meramente económicas relacionadas con la capacidad del posible solicitante o con el nivel de los recursos comunales. No parece desacertado pensar que en muchos casos estas comunidades concejiles al intentar frenar la inmigración no sólo estuvieran defendiendo sus intereses económicos o sociales, sino también

45 RuBio Pérez, L. M. (1993). El sistema político... Op. cit., p. 84. En este sentido resulta muy significativo un capítulo de ordenanza del lugar de Ferreras del Puerto que se añade el 28 de abril de 1713, "por hallarnos con mucha vecindad y los términos muy cortos". Así, se va a acordar "para desde dicho día en adelante por capitulo de ordenanza que cualquiera que pretendiere ser vecino en dicho lugar siendo de fuera aparte y no hijo de vecino haya de justificar para serlo ser de buenos tratos y costumbres, pacifico, calidad y vivienda y no siendo asi que no se le admita por tal vecino en poca ni en mucha parte y si lo justificare y entrare cualquiera que fuere, haya de dar una comida de pan, vino y carne por vista de cuatro hombres nombrados por el regidor que fuere de dicho lugar para que vean si es de calidad lo uno y lo otro, y que haya de asistir uno de los vecinos que fuere nombrado por el tal regidor para que asista a dicha comida, y si alguna cosa faltare de comida o bebida, siendo pedido sin pasión por cualquiera vecino se ha de demandar entero cumplimiento de todo de forma que no haya falta alguna, y demás haya de pagar el tal forastero que asi entrare por vecino cincuenta reales de vellón y ha de tener obligación el tal pretendiente de manifestarlo al concejo ocho días antes que se le reciba para que el regidor haga juntar su gente y se tome providencia en le particular. $Y$ el hijo de vecino que entrare por tal sólo ha de pagar lo acostumbrado, como es una cántara de vino, cuatro panes y tres ducados en dinero y no más". En San Martín se trata de limitar la entrada de nuevos vecinos "por cuanto este dicho lugar se halla muy corto de término y pasto boyal para la conservación de sus ganados y de los montes por estar tan contiguo a los demás lugares circunvecinos, y asimismo empeñado en un censo de tres mil setecientos cuarenta reales poco más o menos, que dicho concejo y vecinos tiene contra sí de principal a favor de D. Gregorio Díaz Santos, vecino de la villa de Guardo, el cual dicho censo se sacó por el referido concejo para la compra y quita de la redención de las alcabalas que dicho lugar pagaba a Su Majestad (que Dios guarde) de que se halla hoy exento, por cuyas razones, y que no se puede conservar con mucha copia de vecinos que en él hay (...)". 
librándose de la competencia sobre todo a la hora de demandar, pujar y presionar sobre los bienes de producción arrendados por ellos a los grupos rentistas ${ }^{46}$.

Para concluir el presente trabajo, añadiremos que dentro de las prácticas o realizaciones colectivas que desarrollan las sociedades rurales tradicionales, las "hacenderas" son las que mejor tipifican la organización comunitaria y las obligaciones individuales que subyacen en el derecho de vecindad para con la comunidad. Este tipo de prestaciones realizadas desde el ámbito concejil parece estar relacionado con antiguas prestaciones señoriales colectivas y posteriormente con el mayor desarrollo de una agricultura en la que se exige la interdependencia de las unidades productivas y de éstas con el conjunto comunitario. El calendario laboral y el inicio del año agrícola marcan unas pautas de acción colectiva que afecta a caminos, regueros, o pasos, junto a otros trabajos comunitarios como el riego de praderas comunales, la conservación y limpieza de ríos y montes o la vigilancia de los frutos ${ }^{47}$.

${ }^{46}$ Rubio PÉREZ, L. M. (1993). El sistema político... Op. cit., p. 85-87.

${ }^{47}$ En lo que respecta a los caminos, el cap. 30 de Prado indica "que los regidores que son y fueren de dicha villa, hagan tener los caminos aderezados para el día que cumplieren, y si así no lo hicieren paguen de pena dos azumbres de vino". En San Martín, cap. 13: "que un día de cada mes se vaya a la hacendera de los caminos reales y concejiles exceptuando en los cuatro meses feriales como son julio, junio, agosto y septiembre, y asimismo cada semana de Cuaresma el día viernes se vaya al reparo de los dichos caminos y vayan a lo uno y otro peones suficientes y el que a ello faltare pague de pena dos reales excepto que tenga legítimo impedimento de becerías mayores o enfermedad en que se halle ausente". 